\title{
The Comparasion Tenofovir Disoproxil Fumarate with Telbivudine in Preventing Hepatitis B Transmission in Mothers with High Viral Load: A Retrospective Cohort Study
}

\section{Ming Wang}

Capital Medical University Beijing Obstetrics and Gynecology Hospital

\section{Yunxia Zhu}

Capital Medical University Youan Hospital

\section{Qiumei Pang}

Capital Medical University Youan Hospital

Ran Li

Capital Medical University Youan Hospital

Hua Zhang ( $\nabla 13717850635 @ 163 . c o m)$

Beijing Youan Hospital, Capital Medical University. https://orcid.org/0000-0003-0727-7478

\section{Research article}

Keywords: mother-to-child transmission, Hepatitis B virus, alanine aminotransferase, antiviral therapy

Posted Date: October 17th, 2019

DOI: https://doi.org/10.21203/rs.2.14867/v2

License: (1) This work is licensed under a Creative Commons Attribution 4.0 International License. Read Full License 


\section{Abstract}

Background Little observational data exist regarding the comparasion of efficacy and safety between tenofovir disoproxil fumarate(TDF) and Telbivudine(Ldt) in late pregnancy on preventing hepatitis B motherto-child transmission (MTCT) in real-world settings.Methods We retrospectively enrolled HB-s antigen (HBsAg) positive mothers with HBV DNA $\geq 2 * 105 \mathrm{IU} / \mathrm{mL}$ to receive TDF or LdT after gestational weeks 24 32 weeks. All infants received standard immunoprophylaxis. The primary outcomes were the MTCT rates at infants' age of 52 weeks and the safety of TDF or LdT use. The secondary outcomes were the decline of HBV-DNA levels at delivery and the rates of on-treatment and off-treatment alanine aminotransferase (ALT) elevation>2 uper limit normal(ULN) during the study.Results of 1407 patients enrolled, 209 patients received TDF treatment and 1198 patients received LdT treatment. There were no difference between the mean duration of TDF and Ldt treatment (TDF vs.LdT: $11.76 \pm 2.20$ weeks vs $11.64 \pm 2.79$ weeks, $P>0.05)$.At birth, $9.8 \%$ of infants in the TDF-treatment group were HBsAg positive, lower than $20.8 \%$ in the LDT-treatment group $(P<0.001)$. Among 1405 infants ( $T D F / L d T=213 / 1192)$ of the 1385 (TDF/LdT $=205 / 1180)$ patients completed the 52-week study, intention-to-treat analysis indicated $0.5 \%$ (1 infant was lost to follow-up) in TDF treated mother and $0.3 \%$ in LDT treated mothers (3 infant was lost to follow-up). There was no difference between TDF group and $L d T(P>0.05)$. On-treatment analysis indicated $0 \%$ of HBsAg positive infants in the three group $(P>0.05)$. The levels of HBV-DNA decline in TDF-treated mothers were observed comparable in LdT treated mother $(4.05 \pm 0.93 \log 10 \mathrm{IU} / \mathrm{ml}$ vs.3.99 $\pm 1.30 \log 10$ $\mathrm{IU} / \mathrm{ml}, \mathrm{P}>0.05)$.TDF treated mothers had complained more symptoms of .nausea,anorexia and dizziness and less arthralgia than LdT treated mothers. All the adverse events of three groups were grade I-II.Alanine aminotransferase (ALT) elevation(>2ULN) in TDF-treated mothers were observed lower in TDF-treated mothers than LdT-treated mothers $(7.3 \%$ vs. $15.7 \%, P<0.05)$. Alanine aminotransferase flares in TDF-treated mothers were observed lower than LdT-treated mothers(7.3\% vs.15.7\%, P < 0.05). Conclusions TDF and LdT use in late pregnancy for highly viremic mothers was equally effective in reducing MTCT. TDF treated mothers complained more symptoms of disgestive systemmore and had less ALT abnormalities than LdT.

\section{Introduction}

Mother-to-child transmission of hepatitis B virus (HBV) is the major causes of chronic Hepatitis B virus (CHB) which is associated with high rates of liver cirrhosis and hepatocellular carcinoma ${ }^{[1-2]}$. Although reduced from $90 \%$ to approximately $5 \%-10 \%{ }^{[3-4]}$ with combination use of HBV vaccine and Hepatitis $B$ immunoglobulin G, MTCT remains a threat of infants born to women with a high HBV viral load $(>200,000 \mathrm{IU}$ per milliliter) and results in significant numbers of chronic infant infection for a large carrier rates of HBV in Southeast Asian ${ }^{[5-7]}$. Previous studies indicated that inhibiting HBV replication with lamivudine (LAM), telbivudine (LdT) or tenofovir disoproxil fumarate (TDF) during late pregnancy in highly viremic mothers could further reduce the risk of $\mathrm{MTCT}^{[8-10]}$. However, little observational data exists regarding the comparasion of efficacy and safety between tenofovir TDF and Ldt in late pregnancy on preventing MTCT of HBV. 
In our previous study ${ }^{[9]}$, LdT-treated mothers had a mean serum HBV DNA decline $>4 \log 10$ copies $/ \mathrm{mL}$ at deivery after 10.38 \pm 1.02 weeks' treatment, compared to no change in HBV DNA levels for the untreated group $(P<0.001)$.Infants of Ldt-treated mothers had lower HBV MTCT rates than infants of untreated mothers in HBeAg positive mothers with HBV DNA $>6 \log 10$ copies/mL.The incidence of Alanine aminotransferase flares ( $>5$ times baseline level or $>10$ times ULN) were higher in Ldt and LAM treated mothers than untreated mothers ( $(17.1 \%$ vs. $6.3 \%, \mathrm{P}<0.001)$. In the randomised controlled trial (RCT) by Pan et al ${ }^{[10]}$, TDF- treated patients could achieved $3.56 \log 10 \mathrm{IU} / \mathrm{ml}$ HBV DNA reduction of at delivery after $8.57 \pm 0.53$ weeks' treatment and yield a successful result on HBV MTCT in HBeAg positive mothers with an HBV DNA level $>200000 \mathrm{IU} / \mathrm{mL}$. TDF treated patients had more frequent alanine aminotransferase elevations above the normal range than untreated mothers $(45 \%$ vs. $30 \%, P=0.03)$. However, in the real world study about TDF, 7.69\% (11/143) mothers had ALT increased after TDF cessation ${ }^{[11]}$., which were lower than in the study about Ldt ${ }^{[9]}$.

Because there was lack of the comparasion of the MTCT rates in different NAs treated population and the same criteria of abnormal ALT elevation in these studies. We conducted a retrospective cohort study with a sample size of 1637 patients to to assess the safety and efficacy of third-trimester use of TDF versus LdT, based on the patient-physician decision in a real-life MTCT prevention setting.

\section{Materials And Methods}

\section{Study design and Patient Selection}

We conducted a retrospective cohort study to assess the safety and efficacy between TDF and LdT on MTCT in mothers with CHB at Beijing YouAn Hospital, China. The research site is a tertiary infectious disease hospital and devoted to prevent HBV MTCT for 20 years. Eligible consecutive patients were retrospectively screened from January 1, 2012 to September 31, 2018.The study were approved by theEethics Committee of Beijing YouAn Hospital , Capital Medical University (approval number: Jing-you-kelun-zi [2016]15-hao) at February 2016. The study was conducted according to International Conference Harmonization Good Clinical Practice guidelines and the Declaration of Helsinki.

Pregnant subjects were screened for the following eligibility criteria: age between 20 and 45 years; HBs antigen (HBsAg) and HBeAg positivity; HBV DNA levels $\geq 2 * 10^{5} \mathrm{IU} / \mathrm{mL}$; written the informed consent before treatment;antiviral therapy started on oral LdT $600 \mathrm{mg}$ or TDF $300 \mathrm{mg}$ between gestational weeks 24 and 32; paired infants administered $200 \mathrm{IU}$ of HBIg intramuscular within 2 hours of birth and three dose of $10 \mathrm{ug}$ of recombinant HBV vaccinewithin 2 hours of birth, 4 and 24 weeks after birth, respectively. Key exclusion criteria included $A L T \geq 2 * U L N(U L N=40 \mathrm{U} / L)$; the treatment of LAM; co-infection with hepatitis $C, D$, E, or HIV; evidence of hepatocellular carcinoma or cirrhosis; concurrent treatment with immune modulators, cytotoxic drugs, or steroids; evidence of fetal deformity by ultrasound examination.

Patients who had received TDF treatment in late pregnancy on preventing hepatitis MTCT were enrolled into TDF treated group and patients who received Ldt were enrolled into Ldt treated group.

\section{Data Collections and Outcome Measurements}


Demographic and clinical data were extracted from the electronic clinical record and paper charts.Data were assessed at the following time points: 4-week intervals from baseline information to delivery; postpartum weeks 4-8, 12, 24, and 28-52.The following data from the clinic and inpatient services were collected for analysis: age, initiating administration weeks, treatment duration before delivery,pregnancy and obstetric complications, pertinent physical findings and laboratory information which include HBV virological markers, chemistry panel results, and imaging results.

The two primary outcomes were the rates of mother to child transmission and the safety of TDF or LdT use at postpartum week 52. The rate of mother-to child transmission was defined as the proportion of infants who had a serum HBV DNA level of more than 20 IU per milliliter (i.e., above the lower limit of detection) or who were positive for hepatitis B surface antigen (HBsAg) at 52 weeks. The rates of ALT leation were the rates of 2 times ULN during the treatment or follow-up.AEs were graded according to the Common Terminology Criteria for Adverse Events (version 4.0). Cases of a structural defect or other safety reports in newborns or infants were tabulated using data acquired from infant during the prenatal period or the postnatal period up to 28 weeks of age (e.g., ultrasonography examination, reports of birth defects and APGAR scores, measurements from growth charts, and development milestones).Perinatal and partum complications (e.g., hypertensive disorders in pregnancy, gestational diabetes mellitus, fetal growth retardation, premature delivery, premature rupture of membrane and postpartum hemorrhage) were included in the safety analysis.

The secondary outcomes were the decline of HBV-DNA levels at delivery and the rates of on-treatment and off-treatment alanine aminotransferase (ALT) elevation>2 uper limit normal(ULN) during the study.

\section{Statistical Analysis}

Based on the previous study by wang et $\mathrm{al}^{[11]}$ and Zhang et al ${ }^{[9]}$, we estimated that $17.1 \%$ of mothers had ALT elevations after Ldt cessation and $7.69 \%$ after TDF cessation. The number of patients needed to capture the adverse events occurred in $>9.41 \%$ of patients was calculated to be 165 in TDF treated group and 660 in Ldt group (1:4 matched) with a significance level of 0.05 (one-tailed). Considering a $10 \%$ dropout rate in the aforementioned RCT, a sample size of more than 176 in TDF group and 726 in Ldt treated group was a reasonable estimation for the current study.The intention to treatment analysis was defined as analysis included all enrolled patients, including those with protocol deviations. We included all enrolled infants to perform ITT analysis of the MTCT rates. Data of mothers and infants who were lost to follow-up were still included in the analysis.Infants who were lost to follow-up were counted as having treatment failure. Baseline characteristics and laboratory results were summarized for two groups by means of descriptive statistics, including percentage, means \pm standard deviation (SD), and 95\% $\mathrm{Cl}$. For the quantitative variable, the t-test was used to compare group differences. For categorical variables, the chisquare test was used for group comparisons. Significance level was set at $P<0.05$; all data were analyzed by SPSS 23.0 (SPSS, IBM., NewYork).

\section{Results}

\section{Study Population}


1767 pregnant women were screened and 1407 mothers were enrolled into the study. Among the enrolled patients, 209 patients received at least one dose of TDF and 1198 patients received at least one dose of LDT, resulting in 209/1198 patients in the TDF/LDT treated group at the baseline visit. 22 subjects were lost to follow-up after baseline, which included 18 mothers before delivery and 4 during the postpartum period, resulting in 1385 mothers with a 52-week follow-up (TDF/LdT=205/1180). There were 1409 infants born from 1389 mothers (TDF/LdT=206/1183) in this cohort with 20 pairs of twins, and 1405 infants completed the 52-week follow-up.The disposition of our study patients is shown in Figure. 1.The characteristics of mother at baseline and infants at birth were presented in Table 1. The mean ( $\pm S D)$ gestational age at drug initiating was $27.38 \pm 1.84$ weeks and $27.52 \pm 1.13$ weeks in patients who received TDF and LDT ,respectively. The mean (+SD) duration of treatment was $11.76 \pm 2.20$ weeks and $11.64 \pm 2.79$ weeks for patients who received TDF and LDT, respectively.

\section{Efficacy of Mothers and Infants}

Before delivery, the levels of HBV-DNA decline in TDF-treated mothers were observed comparable in LdT treated mother $\left(4.05 \pm 0.93 \log _{10} \mathrm{lU} / \mathrm{ml}\right.$ vs.3.99 $\left.\pm 1.30 \log _{10} \mathrm{lU} / \mathrm{ml}, \mathrm{P}>0.05\right)$.All infants in the study received HBIg with first dose of HBV vaccine within 2 hours of birth and completed the addition two vaccines as per standard of care, except for 4 infant who returned to the local city to complete the third dose of vaccine and was lost to follow up. At birth, the HBsAg positive rate of infants in the TDF-treatment group were lower than in the LDT -treatment group ( $9.8 \%$ vs. $20.8 \%, P<0.001)$.

Among 1409 infants (TDF/LdT=213/1192) of the 1385 (TDF/LdT=205/1180) mothers completed the 52week study (98.5\% retention rate), intention-to-treat analysis indicated $0.5 \%$ ( 1 infant was lost to follow-up) in TDF treated mother and $0.3 \%$ in LDT treated mothers (3 infant was lost to follow-up). There was no difference between TDF group and LdT $\otimes P>0.05 \bigotimes$. On-treatment analysis indicated $0 \%$ of HBsAg positive infants in both group $(P>0.05)$.

\section{Safety Assessment}

All mothers in the current study tolerated treatment well without discontinuation of treatment due to adverse event(s). During the treatment period, 18 mothers (TDF/LdT=15/3) withdrew from the study after receiving the first dose of medication.All withdrawals were for because of family relocation to other cities, except for $1 \mathrm{LdT}$ treated patient who experienced grade II AE (mild skin rash and a few episodes of vomiting) and voluntarily withdrew from the study.

There were 19 itemized AEs recorded based on the maternal complaints, physical findings and laboratory abnormalities, which included Headache, Dizziness, Insomnia, Nausea, Abdominal distension, Anorexia or Dyspepsia, Arthralgia, Back pain, Cough, Diarrhea, Epigastric pain, Fatigue, Lower abdominal pain, Myalgia, Pruritus, Pyrexia, Rash, Creatine kinase elevation(Table 2) and ALT elevationهTable 3). Compared to AEs in LdT treated group, nausea,anorexia and dizziness occurred more often in TDF treated patients. However, more mothers complained of arthralgia in LdT treated group than in TDF treated group. All AEs reported were grade $\mathrm{I}-\mathrm{II}$ and there were no maternal severe AEs observed in three group. There were no differences in the incidence of other AEs between TDF treated mothers and LdT treated mothers. 
There was no difference in the ALT elevation between TDF and LDT treated mothers ( $1 \%$ vs. $0.7 \%, P=0.647$ ) during the treatment.(Table 3). Also, no difference were found in the levles of ALT elevation between TDF and LDT treated mothers (190.95 \pm 4.45 , vs. 165.13 $\pm 142.68, \mathrm{P}=0.821)$. As per protocol, 1379 patients (TDF/LdT; $n=204 / 1175)$ stopped antiviral therapy at postpartum week 4. $6.4 \%(13 / 204)$ of patients had offtreatment ALT elevations in TDF treated mothers which were lower than in $15.3 \%(180 / 1175) L d T(P=0.001)$. However, no difference were found of the mean (SD) levels between TDF and LDT treated mothers (222.04 \pm 205.91 vs. $147.78 \pm 90.86, \mathrm{P}>0.05)$. All patients normalized by postpartum week 16 .

There were no significant differences in gestational weeks between TDF -treated and LdT-treated patients (39.15 \pm 1.38 vs. $39.15 \pm 1.39$ weeks, $P=0.992)$. Also the incidences of postpartum hemorrhaging ( TDF vs. LdT: $1.9 \%$ vs. $2.3 \%, P=0.959$ ), and rates of cesarean section (TDF vs. LdT: $43.9 \%$ vs.46.8\%, $P=0.441$ ), respectively. The majority of mothers who had caesarean section had the following top three indications: caesarean section performed on previous delivery, failure to progress from the first to the second stage of labour, and foetal distress during labour. No significant differences were found in terms of infants' weights, heights, or Apgar scores (Tables 1).No mothers received amniocentesis during pregnancy. 1 infant in TDF group had fracture of humerus. There were no differences in neonatal asphyxia, full-term low birth weight infants, premature, pathological jaundice and pneumonia. No other severe AEs in infants were found in both groups and no differences were found in terms of infants' heights and APGAR scores. Congenital deformities was reported in $0.3 \%$ of infants in the LdT group: 1 infant had unilateral cleft palaten, right hand polydactyly and 1 had sacral fissure. No other congenital deformities were found in the newborns of TDF treated group. (Tables 4).All mothers followed the instructions of no breastfeeding during treatment.

\section{Discussion}

In this study, we report the data on different antiviral drugs for preventing MTCT in highly viremic mothers in real-world setting, which is the first and largest real-life study about the comparasion of antiviral treatment between TDF and LdT in pregnant mothers. TDF or LdT were recommended to prevent MTCT in high viremic population during pregnancy in many guidelines for the managementof chronic HBV infection. However, there is no priority recommendation among them for the lack of regarding studies on the selection of TDF or $\operatorname{LdT}^{[6,12-15]}$.

The use of TDF and LdT during pregnancy yielded 100\% successful rate of preventing MTCT in the on protocol analysis in our real-life setting, respectively.Same to previous studies ${ }^{8-10,16-18}$, our data further support the use of TDF, or LdT during late pregnancy on preventing MTCT in CHB mothers with high levels of HBV DNA. At birth, the HBsAg positive rate of infants in the TDF-treatment group were lower than in the LDT -treatment group. The mean gestational age at drug initiating and duration of treatment was similar between patients who received TDF and LDT. Before delivery, the levels of HBV-DNA decline in TDF-treated mothers $\left(4.05 \pm 0.93 \log _{10} \mathrm{IU} / \mathrm{ml}\right)$ were observed comparable in LdT treated mother $(3.99 \pm 1.30 \mathrm{log} 10 \mathrm{lU} / \mathrm{m})$. At birth, the HBsAg positive rate of infants in the TDF-treatment group were lower than in the LDT -treatment group (9.8\% vs. $20.8 \%, P<0.001)$. 
Many studies ${ }^{[8-11,19-20]}$ observed the safety profiles of LdT or TDF and the antiviral treatment were tolerated well during pregnancy. There were no differences in the rates of birth defect and fetus or infant complication between patients received TDF or LdT antiviral treatment and none antiviral treatment during pregnancy. However, previous study was underpowered to evaluate potentially small differences in birth-defect rates. Our study, with a much larger sample size of infants (TDF/LdT=214/1195), identified a similar AEs profile with those data published in previous studies ${ }^{[8-11,19-20]}$. Although there were no differences between the MTCT rates and birth defect rates, the rates of off-treatment ALT elevations were more often in LdT treated mothers than in TDF- treated mothers. TDF treated mothers had complained more symptoms of .nausea, anorexia and dizziness and less arthralgia than LdT treated mothers. Congenital deformities was reported in $0.3 \%$ of infants in the LdT group which was not higher than the common population ${ }^{[21-22]}$. However, our study is a retrospective cohort study, which need the verification of a prospective study in the future. Besides, our study only included patients in immune tolerance stage and may not be generalizable to patients with abnormal ALT elevation before treatment.

\section{Conclusions}

In conclusion, our results indicated that TDF or LdT treatment yielded the similar success in preventing MTCT in CHB mothers with HBV DNA $\geq 2 * 10^{5} \mathrm{IU} / \mathrm{mL}$ during late pregnancy. TDF had a lower rate of offtreatment ALT elevations than LdT.

\section{Abbreviations}

AE, adverse events; ALT, alanine aminotransferase; CHB, Chronic Hepatitis B; HBeAg, Hepatitis B e-Antigen; HBIg, Hepatitis B immune globulin; HBsAg, Hepatitis B surface Antigen; HBV, Hepatitis B virus; TDF, tenofovir disoproxil fumarate; LdT, Telbivudine; MTCT, mother-to-child transmission; ITT, Intention-to-treat; PP, perprotocol.

\section{Declarations}

\section{Acknowledgements:}

Funding: The design and data collection in this study was supported by a research grant from Major project of Beijing Municipal Science and Technology Commission (grant number: D161100002716004).The writing of the manuscript, statistical analysis, and interpretation of data were supported by Beijing Hospitals Authority Talent Training Plan (grant number: QMS20191706).

We thank our research associates,including Hong We, Lingzhi Chang, Zhiqiang Zhao, Xiang Gao and Xin Zhou in the Department of Obstetrics and Gynecology, Youan Hospital Medical Center, for providing assistance with the data collection.

\section{Author information}

\section{Affiliations}


Department of Gynecologic Oncology, Beijing Obstetrics and Gynecology Hospital, Capital Medical University, Beijing, China

Ming Wang

Department of Obstetrics and Gynecology, Beijing Youan Hospital, Capital Medical University, Beijing, China Ming Wang, Yunxia Zhu, Qiumei Pang, Ran Li, Hua Zhang.

\section{Author Contributions:}

Drs. Zhang and Wang proposed the concept and designed the study. Drs. Zhang and Wang obtained the research funding. Drs Zhang, Wang, Zhu, Pang and Li contributed to the acquisition of data. Dr. Zhang supervised the data collection. Dr Wang performed the statistics, interpreted the data and wrote the manuscript. Dr. Zhang performed critical revision of the manuscript and addressed the comments from the journal.All authors had read and approved the final version of the manuscript.

\section{Ethics declarations:}

Ethical approval: All procedures performed in studies involving human participants were in accordance with the ethical standards of the institutional and/or national research committee and with the 1964 Helsinki declaration and its later amendments or comparable ethical standards. The study were approved by the Eethics Committee of Beijing YouAn Hospital, Capital Medical University (approval name: clinical trial of antiviral therapy in the prevention of mother to child transmission of hepatitis $B$ at stage of middle and late pregnancy in mothers with High Viral Load; approval number: Jing-you-ke-lun-zi [2016]15-hao) at February 2016. All the patients written the informed consent before treatment.

Consent for publication: Not applicable.

Availability of data and materials[The datasets used and/or analysed during the current study are available from the corresponding author on reasonable request.

Conflict of Interest: The authors declare that they have no conflict of interest.

\section{References}

1.Lavanchy D. Hepatitis B virus epidemiology, disease burden, treatment, and current and emerging prevention and control measures. J Viral Hepat 2004; 11: 97-107.

2.Pan CQ, Zhang JX. Natural history and clinical consequences of Hepatitis B virus infection. Int J Med Sci2005;2:36-40.

3.Wiesen E, Diorditsa S, Li X. Progress towards hepatitis B prevention through vaccination in the Western Pacific. 1990-2014.Vaccine 2016; 34:2855-2862. 
4.Zou H, Chen Y, Duan Z, Zhang H, Pan C. Virologic factors associated with failure to passive-active immunoprophylaxis in infants born to HBsAg-positive mothers. J Viral Hepat 2012;19:e18-25.

5.Lee C, Gong Y, Brok J, Boxall EH, Gluud C. Hepatitis B immunisation for newborn infants of hepatitis B surface antigen-positive mothers. Cochrane Database Syst Rev 2006; 2: CD004790.

6.Terrault NA, Bzowej NH, Chang K-M,Hwang JP, Jonas MM, et al. AASLD guidelines for treatment of chronic hepatitis B. Hepatology 2016; 63: 261-83.

7.World Health Organization Western Pacific Regional Office. Eliminating mother to child transmission of HIV, hepatitis and syphilis.August.2018. (https://www.who.int/westernpacific/activities/ eliminating-motherto-child-transmission-of-hiv-hepatitis-syphilis - 90k).

8.Xu WM, Cui YT, Wang L, Yang H, Liang ZQ, et al. Lamivudine in late pregnancy to prevent perinatal transmission of hepatitis B virus infection: a multicentre,randomized, double-blind, placebo-controlled study. J Viral Hepat. 2009;16:94-103.

9.Zhang H, Pan CQ, Pang Q, Tian R, Yan M, et al. Telbivudine or lamivudine use in late pregnancy safely reduces perinatal transmission of hepatitis B virus in real-life practice. Hepatology2014;60:468-476.

10.Pan CQ, Duan Z, Dai E, Zhang S, Han G, et al. Tenofovir to prevent hepatitis B transmission in mothers with high viral load. N Engl J Med 2016;374:2324-2334.12.

11.Ming Wang, Qian Bian, Yunxia Zhu, Qiumei Pang, Lingzhi Chang, et al. Real-world study of tenofovir disoproxil fumarate to prevent hepatitis B transmission in mothers with high viral load.Aliment Pharmacol Ther. 2019; 49(2): 211- 217.

12.Chinese Foundation for Hepatitis Prevention and Control; Chinese Society of Infectious Diseases, Chinese Medical Association; Chinese Society of Hepatology, Chinese Medical Association. [Management algorithm for interrupting mother-to-child transmission of hepatitis B]. Zhonghua Gan Zang Bing Za Zhi 2017;25(4):254-256.

13.Hou J, Cui F, Ding Y, Dou X, Duan Z, et al. Management Algorithm for Interrupting Mother to Child Transmission of Hepatitis B Virus. Clin Gastroenterol Hepatol2018(18)31090-5.

14.Tong MJ, Pan CQ. An expert consensus for the management of chronic hepatitis B in Asian Americans. Aliment Pharmacol Ther 2018;47:1181-1200.

15.European Association for the Study of the Liver. EASL 2017 clinical practice guidelines on the management of hepatitis B virus infection. J Hepatol 2017;67:370-398.

16.Chen $\mathrm{HL}$, Lee $\mathrm{CN}$, Chang $\mathrm{CH}, \mathrm{Ni} \mathrm{YH}$, Shyu MK, et al. Efficacy of maternal tenofovir disoproxil fumarate in interrupting mother-to-infant transmission of hepatitis B virus. Hepatology. 215;62:375-386.20. 
17.Greenup AJ, Tan PK, Nguyen V, Glass A, Davison S, et al. Efficacy and safety of tenofovir disoproxil fumarate in pregnancy to prevent perinatal transmission of hepatitis B virus. J Hepatol. 2014;61:502-507.

18. Han GR, Cao MK, Zhao W, Jiang HX, Wang CM, et al. A prospective and open-label study for the efficacy and safety of telbivudine in pregnancy for the prevention of perinatal transmission of hepatitis $B$ virus infection. J Hepatol. 2011;55:1215-1221.

19. Han GR, Jiang HX, Wang CM, Ding Y, Wang GJ, et al. Long-term safety and efficacy of telbivudine in infants born to mothers treated during the second or third trimesters of pregnancy. J Viral Hepat. 2017;24(6):514-521.

20.APR. Antiviral Pregnancy Registry Interim report 1 January 1989 through 31 January 2018. www.APregistry.com. 2018: Issued in June 2018. Accessed October 2018.

21.Pei L, Zeng L, Zhao Y, Wang D, Yan H.Using latent class cluster analysis to screen high risk clusters of birth defects between 2009 and 2013 in Northwest China. Scientific Reports 2017, 7(1):6873.

22.Zhao DD, Dai YX, Guo LQ, Liu R, Wang HL,et al. Association between illness and mental status in pregnant women and birth defects. Zhonghua Liu Xing Bing Xue Za Zhi 2017:1460-1465.

\section{Tables}

\section{Table 1. Maternal and Infant Baseline Values}




\begin{tabular}{|c|c|c|c|}
\hline $\begin{array}{l}\text { Median (range) } \\
\text { Mothers }\end{array}$ & $\begin{array}{l}\text { TDF Treated } \\
(\mathrm{n}=209)\end{array}$ & $\begin{array}{l}\text { LDT Treated } \\
(n=1198)\end{array}$ & TDF vs.LdT \\
\hline Age (years) & $29.96 \pm 4.28$ & $28.04 \pm 4.14$ & $\mathrm{t}=6.124, \mathrm{P}<0.001$ \\
\hline HBV DNA ( Log10 IU/mL) & $7.93 \pm 0.67$ & $7.42 \pm 0.76$ & $\mathrm{t}=9.886, \mathrm{P}<0.001$ \\
\hline ALT ( U/L) & $20.90 \pm 12.48$ & $21.98 \pm 11.65$ & $\mathrm{t}=1.227, \mathrm{P}=0.220$ \\
\hline Initiating weeks & $27.38 \pm 1.84$ & $27.52 \pm 1.13$ & $\mathrm{t}=1.047, \mathrm{P}=0.296$ \\
\hline Administration weeks & $11.76 \pm 2.20$ & $11.64 \pm 2.79$ & $\mathrm{t}=0.713, \mathrm{P}=0.477$ \\
\hline $\mathrm{HBsAg} \square \mathrm{IU} / \mathrm{ml}$ & $21797.89 \pm 21591.73$ & $9592.73 \pm 16347.30$ & $t=7.583, P<0.001$ \\
\hline $\mathrm{HBeAg} \square \mathrm{COI} / \mathrm{mll}$ & $1592.89 \pm 686.52$ & $1299.42 \pm 518.71$ & $\mathrm{t}=5.736, \mathrm{P}<0.001$ \\
\hline $\begin{array}{l}\text { HBV DNA decline Log10 } \\
(\mathrm{IU} / \mathrm{mL})\end{array}$ & $4.05 \pm 0.93$ & $3.99 \pm 1.30$ & $\mathrm{t}=0.677, \mathrm{P}=0.499$ \\
\hline Infants & $\begin{array}{l}\text { TDF Treated } \\
(\mathrm{n}=214)\end{array}$ & $\begin{array}{l}\text { LDT Treated } \\
(\mathrm{n}=1195)\end{array}$ & TDF vs.LdT \\
\hline Gestational age (weeks) & $39.15 \pm 1.38$ & $39.15 \pm 1.39$ & $t=0.011, P=0.992$ \\
\hline Cesarean Section (\%) & $94 \llbracket 43.9 \square$ & $559 \square 46.8 \square$ & $\mathrm{X}^{2}=0.594, \mathrm{P}=0.441$ \\
\hline Infants' weight (kg) & $3266.59 \pm 428.88$ & $3305.52 \pm 438.39$ & $\mathrm{t}=1.152, \mathrm{P}=0.249$ \\
\hline HBsAg+ at birth (\%) & $21 \square 9.8 \square$ & $248 \square 20.8 \square$ & $\begin{array}{c}\mathrm{X}^{2}=14.06 \\
\mathrm{P}=1.77 * 10-4\end{array}$ \\
\hline $\mathrm{HBeAg}+$ at birth(\%) & 186(86.9) & $1090(91.2)$ & $\mathrm{X}^{2}=3.92, \mathrm{P}=0.048$ \\
\hline Detectable HBV-DNA -no.(\%) & 0 & 0 & $* * \mathrm{P}=1$ \\
\hline MTCT rate (\%)*-ITT & $1 \square 0.5 \square$ & $3 \square 0.3 \square$ & $* * \mathrm{P}=0.483$ \\
\hline MTCT rate (\%)*-pp & $0 / 213$ & $0 / 1192$ & $* * \mathrm{P}=1$ \\
\hline
\end{tabular}

*Note: ITT, Intention-to-Treat Analysis; PP, Per protocol analysis.**Fisher's exact test. ALT, alanine aminotransferase; HBeAg, Hepatitis B e-Antigen; HBsAg, Hepatitis B surface Antigen; HBV, Hepatitis B virus; TDF, tenofovir disoproxil fumarate; LdT, Telbivudine; MTCT, mother-to-child transmission; ITT, Intention-to-treat; PP, per-protocol.

Table 2. Maternal Adverse Events Reported in the Study 


\begin{tabular}{|c|c|c|c|}
\hline Adverse Events N (\%) & $\begin{array}{l}\text { TDF Treated } \\
(\mathrm{n}=209)\end{array}$ & $\begin{array}{l}\text { LdT Treated } \\
(n=1198)\end{array}$ & $\begin{array}{l}\text { P-value } \\
\text { TDF vs.LdT }\end{array}$ \\
\hline \multicolumn{4}{|l|}{ Grade 1-2 } \\
\hline Headache & $5(2.4)$ & $42(3.5)$ & $\mathrm{X}^{2}=0.683, \mathrm{P}=0.408$ \\
\hline Dizziness & $17(8.1)$ & $52(4.3)$ & $\mathrm{X}^{2}=5.491, \mathrm{P}=0.019$ \\
\hline Insomnia & $8(3.8)$ & $70(5.8)$ & $\mathrm{X}^{2}=1.380, \mathrm{P}=0.240$ \\
\hline Nausea & $31(14.8)$ & $103(8.6)$ & $\mathrm{X}^{2}=8.028, \mathrm{P}=0.005$ \\
\hline Abdominal distension & $5(2.4)$ & $23(1.9)$ & $\mathrm{X}^{2}=0.204, \mathrm{P}=0.652$ \\
\hline Anorexia & $37(17.7)$ & $65(5.4)$ & $\mathrm{X}^{2}=39.895, \mathrm{P}<0.001$ \\
\hline Arthralgia & $2(1.0)$ & $87(7.3)$ & $\mathrm{X}^{2}=12.063, \mathrm{P}=0.001$ \\
\hline Back pain & $3(1.4)$ & $7(0.6)$ & $* \mathrm{X}^{2}=0.082, \mathrm{P}=0.365$ \\
\hline Cough & $1(0.5)$ & $7(0.6)$ & $* \mathrm{X}^{2}=0, \mathrm{P}=1$ \\
\hline Diarrhea & $1(0.5)$ & $11(0.9)$ & $* \mathrm{X}^{2}=0.053, \mathrm{P}=0.818$ \\
\hline Epigastric pain & $3(1.4)$ & $15(1.2)$ & $* \mathrm{X}^{2}=0, \mathrm{P}=1$ \\
\hline Fatigue & $2(1.0)$ & $17(1.4)$ & $* \mathrm{X}^{2}=0.044, \mathrm{P}=0.834$ \\
\hline Lower abdominal pain & $1(0.5)$ & $15(1.3)$ & $* \mathrm{X}^{2}=0.384, \mathrm{P}=0.353$ \\
\hline Myalgia & $0(0)$ & $5(0.4)$ & $* * \mathrm{P}=1$ \\
\hline Pruritus & $1(0.5)$ & $13(1.1)$ & $* \mathrm{X}^{2}=0.192, \mathrm{P}=0.662$ \\
\hline Pyrexia & $2(1.0)$ & $10(0.8)$ & $* \mathrm{X}^{2}=0, \mathrm{P}=1$ \\
\hline Rash & $0(0)$ & $16(1.3)$ & $* \mathrm{X}^{2}=1.760, \mathrm{P}=0.185$ \\
\hline Creatine kinase elevation & $1(0.5)$ & $15(1.3)$ & $* \mathrm{X}^{2}=0.384, \mathrm{P}=0.535$ \\
\hline Infants & $\begin{array}{l}\text { TDF Treated } \\
(\mathrm{n}=214)\end{array}$ & $\begin{array}{l}\text { LDT Treated } \\
(\mathrm{n}=1195)\end{array}$ & $\begin{array}{l}\text { P-value } \\
\text { TDF vs.LdT }\end{array}$ \\
\hline Deformity & $0(0)$ & $3(0.3)$ & $* * \mathrm{P}=1$ \\
\hline Humeral fractures & $1(0.5)$ & $0(0)$ & $* * \mathrm{P}=0.152$ \\
\hline Neonatal asphyxia & $1(0.5)$ & $5(0.4)$ & $* * \mathrm{P}=1$ \\
\hline
\end{tabular}


Full-term low birth weight infants 4(1.9)

Preterm delivery

Fetal macrosomia

Pathological Jaundice

Pneumonia
$14(6.5)$

$7(3.3)$

$8(3.7)$

$5(2.3)$
15(1.3)

$64(5.4)$

$62(5.2)$

47(3.9)

$51(4.3)$
$* \mathrm{X} 2=0.156, \mathrm{P}=0.693$

$\mathrm{X} 2=0.489, \mathrm{P}=0.485$

$\mathrm{X} 2=1.433, \mathrm{P}=0.231$

$\mathrm{X} 2=0.018, \mathrm{P}=0.892$

$\mathrm{X} 2=1.749, \mathrm{P}=0.186$

*Continuety correction;** Fisher's exact test. TDF, tenofovir disoproxil fumarate; LdT, Telbivudine.

Table 3. ALT Flares in TDF and LdT Treated Mothers

\begin{tabular}{|c|c|c|c|}
\hline ALT flares & $\begin{array}{l}\text { TDF-Treated } \\
(\mathrm{n}=205)\end{array}$ & $\begin{array}{l}\text { LDT-Treated } \\
(\mathrm{n}=1198)\end{array}$ & $\begin{array}{l}\text { P-value } \\
\text { TDF vs.LdT }\end{array}$ \\
\hline On Treatment, n (\%) & $2 / 205(1)$ & $8 / 1198(0.7)$ & $* * \mathrm{P}=0.647$ \\
\hline $\begin{array}{l}\text { On Treatment abnormal ALT } \\
\text { levels } \square I U / L \square\end{array}$ & $190.95 \pm 4.45$ & $165.13 \pm 142.68$ & $\mathrm{t}=0.241, \mathrm{P}=0.821$ \\
\hline Off-Treatment, $\mathbf{n}(\%)$ & $13 / 204(6.4)$ & $180 / 1175(15.3)$ & $\mathrm{X}^{2}=11.56, \mathrm{P}=0.001$ \\
\hline $\begin{array}{l}\text { Off-Treatment abnormal ALT } \\
\text { levels } \square I U / L \square\end{array}$ & $\begin{array}{l}222.04 \pm \\
205.91\end{array}$ & $147.78 \pm 90.86$ & $t=1.158, P=0.262$ \\
\hline Any time during the study period & $15 / 205(7.3)$ & 188/1198(15.7) & $\mathrm{X}^{2}=9.923, \mathrm{P}=0.002$ \\
\hline $\begin{array}{l}\text { Abnormal ALT levels during the } \\
\text { study period } \square \mathrm{IU} / \mathrm{L} \square\end{array}$ & $\begin{array}{l}210.75 \pm \\
190.65\end{array}$ & $147.79 \pm 91.37$ & $t=1.176, P=0.261$ \\
\hline
\end{tabular}

** Fisher's exact test. ALT, alanine aminotransferase; TDF, tenofovir disoproxil fumarate; LdT, Telbivudine.

\section{Figures}




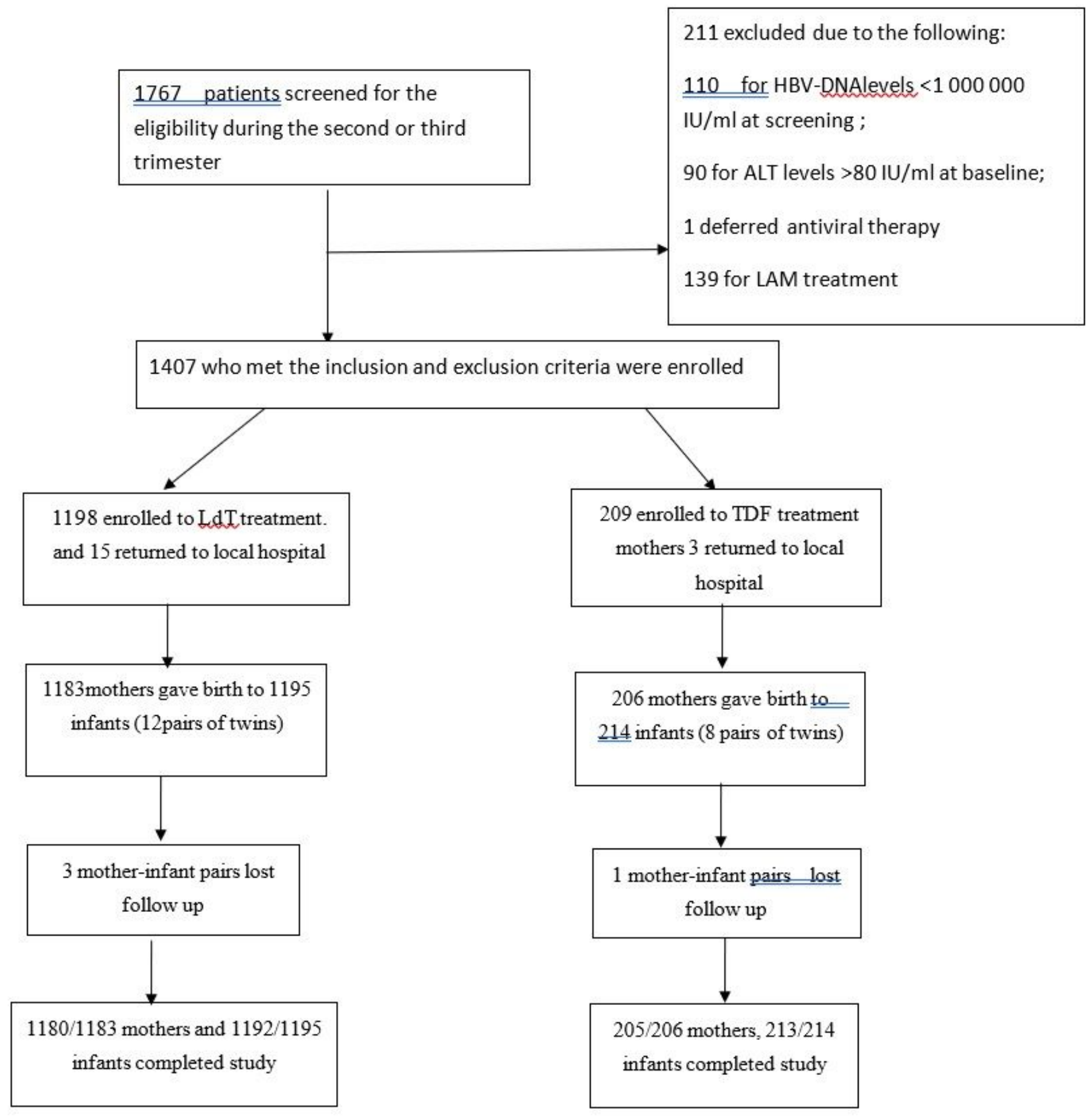

Figure 1

Disposition of mothers and infants

\section{Supplementary Files}

This is a list of supplementary files associated with this preprint. Click to download.

- STROBEChecklist.pdf 